Article

\title{
Portfolio Construction by Using Different Risk Models: A Comparison among Diverse Economic Scenarios
}

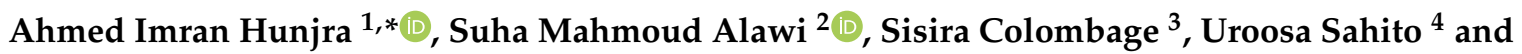 \\ Mahnoor Hanif ${ }^{1}$ (D) \\ 1 University Institute of Management Sciences-PMAS-Arid Agriculture University Rawalpindi, Rawalpindi, \\ Punjab 46000, Pakistan; mahnoorhanif289@gmail.com \\ 2 Department of Finance, Faculty of Economics and Administration, King Abdulaziz University, \\ Jeddah 22322, Saudi Arabia; Salawi@kau.edu.sa \\ 3 Federation Business School, Federation University Australia, Clyde Road, Berwick, VIC 3806, Australia; \\ sisira.colombage@federation.edu.au \\ 4 Department of Business Administration, University of Sufism and Modern Sciences Bhitshah, \\ Sindh 70140, Pakistan; uroosa.sahitooo@gmail.com \\ * Correspondence: ahmedhunjra@gmail.com or ahmed.imran@uaar.edu.pk
}

Received: 8 October 2020; Accepted: 23 November 2020; Published: 30 November 2020

\begin{abstract}
We aim to construct portfolios by employing different risk models and compare their performance in order to understand their appropriateness for effective portfolio management for investors. Mean variance (MV), semi variance (SV), mean absolute deviation (MaD) and conditional value at risk $(\mathrm{CVaR})$ are considered as risk measures. The price data were extracted from the Pakistan stock exchange, Bombay stock exchange and Dhaka stock exchange under diverse economic conditions such as crisis, recovery and growth. We take the average of GDP of the selected period of each country as a cut-off point to make three economic scenarios. We use 40 stocks from the Pakistan stock exchange, 92 stocks from the Bombay stock exchange and 30 stocks from the Dhaka stock exchange. We compute optimal weights using global minimum variance portfolio (GMVP) for all stocks to construct optimal portfolios and analyze the data by using MV, SV, MaD and CVaR models for each subperiod. We find that CVaR (95\%) gives better results in each scenario for all three countries and performance of portfolios is inconsistent in different scenarios.
\end{abstract}

Keywords: mean variance; semi variance; mean absolute deviations; conditional value at risk; stock market; portfolio construction

\section{Introduction}

Portfolio construction is considered to be one of the main concerns in securities investment as the future returns are uncertain. Portfolio selection is an ex-ant decision procedure. Despite the fact that risk is inevitable in every aspect of life, undertaking strategies to minimize risk has become an essential part of life. In finance, the risk is the possibility of deviation identified with the inconstancy of future returns (Artzner et al. 1999). The role of proper risk management of a portfolio of financial assets or securities has been recognized in the literature. Thus, the concerns relate back to the era of Markowitz's (1959) portfolio selection model which is the foundational framework of portfolio selection with optimal risk-return trade-off. In the last decade, the development of trading activities has provided new methods of underscoring the necessity for market participants to manage the risk.

Markowitz (1952) establishes a quantitative paradigm, leading to the first ever mean risk models to incorporate different classes of assets into a portfolio. He further suggests historical variance as 
a measure of risk. Moreover, Markowitz utilizes this in a more computational model by measuring portfolio risk by the covariance framework identified with the individual asset returns. On occasion, variance is criticized as a measure of risk, most commonly for its deliberate nature and for the irregularity with aphoristic models for decision (semi variance, mean absolute deviation and stochastic predominance). This motivates the development of alternative risk measures, and Markowitz's mean variance (MV) model worked as the premise for numerous other models which utilize its essential assumptions (Bodie et al. 2011; Elton et al. 2007).

Efficient risk measurement strategies punish attractive (upside) deviations from the mean same way as they punish undesirable (drawback) deviations. Owing to this criticism, Markowitz (1959) proposes the semi variance as a risk estimation method. The semi variance gives a measure of the variance of the returns that remains below the normal return. As such, rational investors seem more responsive towards downside deviations in relation to upside deviations. Hence, SV is a preferred risk indicator (Chow and Denning 1994; Grootveld and Hallerbach 1999; Markowitz et al. 1993). Konno and Yamazaki (1991) recommend the mean absolute deviation (MaD) model as another risk evaluation measure. Unlike, the mean variance (MV) model, which is a quadratic model, the MaD model is a linear programming model that generally can handle portfolios of fewer assets, and it gives more efficient results than the MV model (Liu and Gao 2006). The conditional value at risk (CVaR) model (also identifies as a mean excess loss, tail VAR) was proposed by Rockafellar and Uryasev (2000). It can be described as the conditional loss estimation over that sum $\alpha$ at a predefined likelihood level $\beta$ (Lim et al. 2011). This technique fulfills all premises of coherent risk.

The approaches adopted by portfolio managers for optimizing portfolios can be classified into two broad groups. First, managers opted for an active strategy attempt to outperform the market by generating portfolios that are designed in a more unique manner than the index. The goal is to achieve a higher return whilst assuming lower or same risk as that of market, or to assume lower risk of the higher or same returns as that of the market. However, index tracking is a passive management strategy. Tracking an index of the stock market involves generating a portfolio that simulates the index's performance. The portfolio generated is referred to as a tracking portfolio, and the tracked index is sometimes referred to as a benchmark (García et al. 2018). However, passive managers tacitly presume that it is not possible to outperform the risk-return combo of the market. The solution to the issue is therefore distinct from that applied by Markowitz's MV model, where the construction of the portfolio is determined by an optimization model method. However, managers using passive strategies tend to lower the level of adjustments to their portfolios and perform tasks only to redesign them in order to comply with the index's composition. Portfolios created using the MV model or index tracking vary considerably. The global portfolio risk is mitigated in the mean variance model, while only the unsystematic risk portion is mitigated in the index tracking method.

A well-developed stock market ensures a strong economy. Stock markets are volatile in nature and highly affected by the cost of borrowing. As the cost of borrowing rises, businesses become unstable and incapable of investing funds further, which in turn has a direct impact on their profit margins. The decline in the level of profit also causes decline in stock prices, making it difficult for investors to find attractive investments in a risky stock market environment. The stock market comes as a medium to facilitate the investors and borrowers by providing a platform to exchange and mobilize funds to different economic sectors (Jaaman et al. 2013). This study examines the performance of the above-mentioned portfolios covering the stock markets of three fast-growing emerging markets of South Asia i.e., Pakistan, India and Bangladesh.

Byrne and Lee (2004) carried out research to affirm the validity of different risk measures in portfolio construction and made a comparison of parameters. They propose that all risk measures perform in a diversified manner and have their own merits and demerits. So, the model selection depends not on the model's theoretical merits over the other but on the attitude of individual towards risk. This may be the reason for not using alternative risk measures frequently. The mean variance that is used in portfolio optimization models may be due to the difficulty in deciding the appropriate 
risk measure and continuous comparison of different risks measures until a common risk measure is brought into action. To outsource this, comparing the portfolio holdings generated by diverse risk measures, instead of the risk return trade-off, is utilized. The results show that the portfolio structures generated by diverse risk measures vary from one another. They propose that choosing a model depends highly on the risk attitude rather than the merits of the model. Having multiple risk modeling alternatives in portfolio optimization, causes various concerns to arise about their legitimacy, utilization and applicability. Specifically, a question arises regarding the barriers of the alternative models with respect to the basic presumption of Markowitz and Todd's (1987) classical model. Comparatively an analysis is made among the classic Markowitz's model and other models that employ Markowitz and Todd's (1987) classic model formulation. There are plenty of unresolved questions related to the selection of different risk models by different investors for risk and return estimation. Do each of these models perform equally well in each different economic scenario? If one model yields better in growth days, does it yield the same results in declining days?

Stock market crises cause investors to be unable to recover their original investments in the stock market, real estate business, and gold and currency market. Government and private sector investment schemes dictate their own behaviors. Moreover, inconsistent policies and strict regulations add fuel to fire. Later on, in money-related crisis, investors have taken a couple of fundamental measures in order to achieve maximum possible return. These measures have driven theorists to give cautious to managing the risk. With these necessities it has become a need of every investor to assess the performance of portfolios under different risk models in different economic scenarios. South Asian emerging markets are an important region to study. For instance, Hunjra et al. (2020) studied profitability of momentum and contrarian tactics incorporating sample of South Asian countries. Given the economic and financial growth in the region over the last two decades (South Asian Financial Market Review 2010), it is an important topic for research. It is of great significance for investors in emerging South Asian countries (Pakistan, Bangladesh and India) to make suitable investment decisions on the performance of portfolios. In this study, analysis of efficient portfolios is conducted by utilizing four different risk measures; the mean variance (MV), semi variance (SV), mean absolute deviation $(\mathrm{MaD})$ and conditional value at risk $(\mathrm{CVaR})$, under three different scenarios of the economy (crisis, recovery, growth). Further comparison of results is performed to understand their relative performance as effective portfolio management technique.

To the best of our knowledge, this study is the first in the context of emerging South Asian countries which compares the portfolio performance constructed by using various risk measures under three different economic scenarios (crises, recovery and growth). The contribution of the paper is two-fold. (i) The outcome of the current study helps to identify if the same risk assessment is applicable in all three substituents or a different risk measure is required for a different sub period. (ii) It provides insights on asset choice, management and the use of an optimal risk model to estimate expected risk and return. The implications of our findings may be beneficial for the investors, investment decision makers and policy makers not only in Pakistan, Bangladesh and India but also those in other emerging economies.

The remainder of the paper is organized as follows. Section 2 offers past studies findings and hypotheses development; Section 3 presents the data, variables and methodology used for the empirical analysis. Section 4 shows the empirical results. Section 5 provides recommendations and concludes the paper.

\section{Literature Review}

Portfolio optimization is a key idea in valuation theories. Markowitz (1952) started additional work for building up a scientific way to deal with multi asset portfolios. Markowitz's (1952) classical model utilizes the relationship of mean and variance of the returns. Markowitz's (1952) expected variance of returns $(\mathrm{EV})$ rule inferred an adequate diversification which relies upon the quantity and diversification of securities crosswise over assets with a specific end goal to reduce variance. Generally, 
firms in a similar industry, as a rule, demonstrate high covariance among themselves as they respond like economic occasions which prompt to a higher risk presentation. Thus, an investor prefers a MV effective portfolio when a given risk level gives the maximum expected return (Campbell et al. 1997). With a specific end goal to decrease or to eradicate the unsystematic risk, the equity allocation must demonstrate an optimal allocation of uncorrelated stocks.

Artzner et al. (1999) introduce the idea of a coherence asset of desired properties for risk measures associated with the tail of distribution. $\mathrm{CVaR}$ is the coherent risk indicator, also called expected shortfall by few authors (Konno et al. 2002; Rockafellar and Uryasev 2000). Despite the amount of studies on risk measures and average risk models, there is still controversy as to which risk measure is the most suitable one. In addition, it continued to challenge the theoretical validity of the mean risk models. Regardless of the number of studies on risk indicators, the topic of which risk measure performs well is still questionable. The Markowitz efficient frontiers (Markowitz 1952) explain how investors select their portfolios maximizing return for a specified amount of risk as measured by the return's variance. A key understanding of this work is that assets should not be chosen exclusively in light of only their exceptional attributes of return and variance. Market specialists need to consider the connection of the portfolio having the same return with lower risk than a portfolio that overlooked these connections (Elton et al. 1997).

Since the early work by Markowitz (1952), optimization models aimed at managing the exchange between risk and return in finance have been studied extensively. According to Filippi et al. (2020), shortfall and quantile risk measures are receiving increasing attention where CVaR is probably the most common of such indicators. Ogryczak and Sliwinski's (2010) study on CVaR finds that the classical Markowitz's model utilizes the variance as the risk measures by providing solution to quadratic optimization issue. Some other studies presented a few option risks measures which are computationally alluring (for discrete random factors) for better understanding of straight programming (SP) issues (Konno and Yamazaki 1991; Rockafellar and Uryasev 2000). The SP reasonability is essential for applications to genuine financial choices where well-developed portfolios need to meet various limitations and consider exchange costs. A range of SP-utilizable risk measures have been introduced in the portfolio construction, albeit the vast majority of them are identified with the outright Lorenz bend and accordingly, the CVaR measures. Ogryczak and Sliwinski (2010) demonstrate that all risk measures are utilized as a part of the SP feasible portfolio improvement models can be taken from the setback criteria. Gluzicka (2010) conducts a research on CVaR and Gini's Mean Difference (GMD) models. GMD is analyzed for different measures of risk such as: variance, semi variance, VaR or CVaR. Different measures of risk are centered on different properties of distribution of returns. For example, the variance measures the deviation of return and the VaR or CVaR measures the possible loss. Gluzicka (2010) studies risk models with two measures (mean and variance) applied for different risk portfolios. He finds that the $\mathrm{CVaR}$ and SV models provide better estimates than MV model. When making comparisons of outcomes from all models it can be mentioned that the models with two measures of risk most often provide better outcomes than the models with only one risk measure (Gluzicka 2010).

Vidovic (2011) conducts a study by characterizing various risk indicators in portfolio composition on seven European stock markets. He identifies that extreme kurtosis and skewness exist in stock returns. Consequently, portfolios employed stocks with high kurtosis and stocks with depreciative skewness. Banihashemi and Navidi (2017) employee CVaR as a risk measure using various confidence level. They compare two measures of risk such as VaR and CVaR to identify the best one for portfolio optimization. They reveal that $\mathrm{CVaR}$ is more accurate than VaR. Further, they indicate that high confidence levels are more accurate than low levels. Jaaman et al. (2013) conducted a study and compared the portfolio construction and performance based on different risk measures using Malaysian Stock returns data in three diverse economic criterions. The study shows multiple optimal portfolios' construction and performances for the three subperiods. However, among the risk models studied, CVaR model gave the peak portfolio skewness and is the most optimal portfolio optimization model. 
Based on the above discussion, it can be said that CVaR model significantly impacts the portfolio performance and this performance is consistent in all scenarios. We can hypothesize it as:

Hypothesis 1 (H1). Conditional value at risk (CVAR) is significantly related to portfolio performance.

Hypothesis 2 (H2). Performance of conditional value at risk (CVAR) is consistent in each economic scenario.

It is evident from the literature that portfolios have different risk criteria so they cannot be easily compared. The reason behind this is that portfolios have different construction, so their performance is also different from one another. This fact has also been proved by Moazeni et al. (2014). All portfolios have different risk criteria, construction and also performance. Soleimani and Govindan (2014) identify that supply chain risk shows better presentations with mean-CVaR models. Baghdadabad (2015) conducts a study to assess the risk accustomed performance of global mutual assets utilizing the risk measurement created by the mean absolute deviation $(\mathrm{MaD})$.

Henriques and Neves (2019) present portfolio optimization framework that considers investment decision under various assumptions of risk. Their findings reflect the risk and return trade-off. In addition, they argue that investors who are less sensitive to risk find the formulation based on mean absolute deviation $(\mathrm{MaD})$ more attractive as it generally offers lower returns variance. According to the study of Baghdadabad (2015), $\mathrm{MaD}$ is one of the important determinants to evaluate the portfolio performance. Moreover, portfolio managers can use the results anywhere in the global stock market. Based on their findings, we hypothesize as follows:

Hypothesis 3 (H3). Mean absolute deviation (MaD) is significantly related to portfolio performance.

Hypothesis 4 (H4). Performance of mean absolute deviation $(\mathrm{MaD})$ is consistent in each economic scenario.

As discussed in the literature, different risk measures have different structures, so their performance also differs from each other. In order to test the performance of different risk measures with the objective of increasing the returns while limiting risk, Gökgöz and Atmaca (2017) examine the different risk measures including mean-variance and semi variance for development in power sectors. According to them, these two models could be associated with all sectors to make efficient points of confinement, diversified portfolios and utility limits. They find that different optimal portfolios offer different return levels to investors with different risk avoidance levels. Recent studies have seen a growing use of the portfolio optimization approach centered on risk/diversification. Mean-diversification efficient frontiers are taken for different diversification measures and portfolios are identified that optimize the risk and return trade-off (Oyenubi 2020). Oyenubi (2020) further claims that these portfolios are better options than the portfolio that is designed to be optimal for mean variance, as they are sensitive to returns. Various measures support the returns while limiting the related market risks. We develop the following hypotheses for our study.

Hypothesis 5 (H5). Mean variance (MV) is significantly related to portfolio performance.

Hypothesis 6 (H6). Semi variance (SV) is significantly related to portfolio performance.

Hypothesis 7 (H7). Performance of mean variance (MV) is consistent in each economic scenario.

Hypothesis 8 (H8). Performance of semi variance (SV) is consistent in each economic scenario. 


\section{Methodology}

Our sample included 40 stocks from Pakistan stock exchange, 92 Stocks from Bombay stock exchange and 30 stocks from Dhaka stock exchange. Summary statistics of all stocks of Pakistan, Bombay and Dhaka stock exchange is given in Tables A1-A3. Based on the availability of complete data, the sample period of our study was from 2003 to 2015. Further, the study period was also of particular significance as it covers before, during and after the financial crisis 2008-09. The global financial tsunami of 2008 has been recognized as one of the century's greatest catastrophes. It has posed many challenges to world social and economic development. However, studies revealed mixed outcomes in terms of impact of GFC on South Asian stock markets (Long et al. 2012; Rastogi 2014). Thus, we are also interested in knowing how the emerging South Asian stock markets performs before, during and after the crisis. The data were comprised of monthly closing prices for every security from January 2003 to the end of December 2015. Only those stocks that were indexed before 2003 and whose complete data were accessible were included. Stocks were extracted from the national stock index which incorporates top performing stocks. Then, we computed a natural logarithm of monthly returns for every stock an individual considered. We employed the global minimum variance portfolio (GMVP) method for optimal portfolio composition (Engle and Kelly 2012). We computed the global minimum variance portfolio weights by computing covariance matrix of return series. We calculated optimal weights for all our stocks under each scenario for Pakistan stock exchange, Dhaka stock exchange and Bombay stock exchange. We analyzed the data by using MV, SV, MaD and CVaR models for each subperiod.

We collected data of the annual GDP from the World Development Indicator (WDI) of selected countries from 2003 to 2015. Annual GDP was converted into monthly GDP by using Eviews. Conversion of annual data is widely accepted and has been applied in large number of studies such as Tang and Chua (2012) and Shahbaz et al. (2014). Following Jaaman et al. (2013), for each country, average of GDP for the selected period was calculated and taken as the cut-off point to make three scenarios; crisis, recovery and growth. The crisis, recovery and growth periods were different for different countries as GDP varied significantly, depending on a variety of factors such as the scale of the economy, the degree of trade openness and the potential for countercyclical policies (Keat 2009). For Pakistan, data from 2003 to 2005 were used as crisis, 2006 to 2011 as recovery and 2012 to 2015 as growth period. For Bangladesh, data from 2006 to 2009 were used as decline, 2010 to 2013 as recovery and 2014 to 2015 as growth period. For India, data from 2004 to 2007 were used as decline, 2008 to 2011 as recovery and 2012 to 2015 as growth period. Each risk measure was applied on a selected country under three different economic scenarios (crises, recovery and growth). As the studies completed in various time periods probably offer various compositions of optimal portfolios (Prakash et al. 2003). The result for each case is presented below in next section.

The models used for estimation are as follows:

The MV model calculates the variation below and above the mean. It not only penalizes the downward deviations but upstream deviations too (Markowitz 1952).

$$
V=\sum_{i=1}^{n} \sum_{j=1}^{n} \sigma i j x_{i} x_{j}
$$

where $\sigma i j$ is the covariance between assets $i$ and $j, x_{j}$ is the amount invested in asset $j$.

Markowitz (1959) proposes semi variance (SV) which centers only on the deviations below the mean. This model penalizes only the downstream deviations not the upward deviations. The semi variance model is presented as:

$$
S V=\frac{1}{T} \sum_{i=1}^{\tau}\left(\max \left[0, E(R)-R_{p t}\right]\right)^{2},
$$


where $t$ is used as the number of periods, $R_{p t}$ is the portfolio return at period $t, E\left(R_{p t}\right.$ is the mean return.

The mean absolute deviation (MaD) model is proposed by Konno and Yamazaki (1991). In this model absolute deviation is used as risk measure to replace variance.

$$
\begin{gathered}
y_{t}+\sum_{j=1}^{n}\left(r_{j t}-r_{j}\right) x_{j} \geq 0, t=1, \ldots, T \\
y_{t}-\sum_{j=1}^{n}\left(j t-r_{j}\right) x_{j} \geq 0, t=1, \ldots, T
\end{gathered}
$$

where $y_{t}$ is the continuous variable that represents the deviations among the mean return of the portfolio as well as return of portfolio at time $t, T$ is the number of period, $r_{j t}$ is the realization of random variable $r_{j}$ during period $t, r_{j}$ is the expected return of asset $j$ per period, $\rho$ is a parameter indicating the minimal rate of return required by an investor and $x_{j}$ is the amount invested in asset $j$.

The conditional value at risk (CVaR) model is presented by Rockafellar and Uryasev (2000) and is also called the mean excess loss, mean shortfall or tail VaR. The CVaR is defined as the conditional expectation of loss beyond that amount $\alpha$ at a given probability level $\beta$ (Lim et al. 2011).

$$
\mathrm{CVaR}=\alpha+\frac{1}{T(1-\beta)} \sum_{t=1}^{\prime} z_{t}
$$

where $\alpha$ is the minimal amount of loss, $\beta$ is the probability that the loss will not surpass $\alpha, T$ is the number of period, $z_{t}$ is the variable, $r_{j t}$ is the realization of random variable $R_{j}$ during period $t, x_{j}$ is the amount invested in asset $j$ and $r_{j}$ is the expected return of asset $j$. In this study, we followed this framework with the selected risk confidence levels $\beta=0.99$ and $\beta=0.95$. Investors seldom experience a loss exceeding $\operatorname{VaR}(\mathrm{X})$ when $\beta$ is 0.99 as compared with 0.95 . CVaR $(0.99)$ means investors have higher downstream risk aversion than CVaR (0.95).

\section{Results}

Tables 1-9 report optimal portfolio compositions for Pakistan (Tables 1-3), Bangladesh (Tables 4-6) and India (Tables 7-9) under economic status of crisis, recovery and growth.

Table 1. Optimal portfolio compositions for economic crisis period (2003-2005).

\begin{tabular}{cccccc}
\hline & MV & SV & MaD & CVaR95\% & CVaR99\% \\
\hline DG KCCL & 0.2313 & 0.1546 & 0.0965 & 0.2661 & -0.0135 \\
DHCL & 0.3527 & 0.3586 & 0.1799 & 0.4029 & 0.0887 \\
NISHAT PCL & 0.2993 & 0.2370 & 0.1512 & 0.2953 & 0.0492 \\
MARI PCL & 0.0886 & 0.0148 & 0.0060 & 0.1841 & -6.3591 \\
NESTLE & 0.1210 & 0.0745 & 0.0101 & 0.2085 & -4.6033 \\
MCB & 0.3641 & 0.3679 & 0.2217 & 0.4060 & 0.0989 \\
\hline
\end{tabular}

Note: Pakistan stock exchange, $\mathrm{MV}=$ mean variance, $\mathrm{SV}=$ semi variance, $\mathrm{MaD}=$ mean absolute deviation, $\mathrm{CVaR} 95 \%=$ conditional value at risk with risk confidence levels $\beta=0.95$ and $\mathrm{CVaR} 99 \%=$ conditional value at risk with risk confidence levels $\beta=0.99$. 
Table 2. Optimal portfolio compositions for economic recovery period (2006-2011).

\begin{tabular}{cccccc}
\hline & MV & SV & MaD & CVaR95\% & CVaR99\% \\
\hline SHELL & 0.0738 & 0.0302 & 0.1446 & 0.0639 & 0.0483 \\
DHCL & 0.0206 & -0.0301 & 0.0859 & 0.0141 & -0.0683 \\
PPL & 0.2049 & 0.0514 & 0.2095 & 0.2527 & 0.1381 \\
FFCL & 0.0302 & 0.0050 & 0.1043 & 0.0243 & 0.0063 \\
KOT ADDU PCL & 0.0349 & 0.0056 & 0.1136 & 0.0269 & 0.0078 \\
\hline
\end{tabular}

Note: Pakistan stock exchange, $\mathrm{MV}=$ mean variance, $\mathrm{SV}=$ semi variance, $\mathrm{MaD}=$ mean absolute deviation, $\mathrm{CVaR} 95 \%=$ conditional value at risk with risk confidence levels $\beta=0.95$ and $\mathrm{CVaR99} \%=$ conditional value at risk with risk confidence levels $\beta=0.99$.

Table 3. Optimal portfolio compositions for economic growth period (2012-2015).

\begin{tabular}{cccccc}
\hline & MV & SV & MaD & CVaR95\% & CVaR99\% \\
\hline DHCL & 0.0141 & 0.0059 & 0.0740 & 0.2021 & -0.4015 \\
NESTLE & 0.0042 & 0.0019 & 0.0447 & 0.0767 & -0.8124 \\
MBL & 0.0032 & 0.0007 & 0.0362 & -0.1710 & -2.8366 \\
NFL & 0.0182 & 0.0063 & 0.0783 & 0.2239 & -0.3625 \\
STD CHARTER & 0.0258 & 0.0091 & 0.1086 & 0.2960 & -0.2859 \\
NISHAT PCL & 0.0067 & 0.0036 & 0.0541 & 0.1351 & -0.4979 \\
LCL & 0.0044 & 0.0021 & 0.0466 & 0.1077 & -0.7360 \\
ABL & 0.0037 & 0.0012 & 0.0433 & 0.0613 & -0.8711 \\
APL & 0.0145 & 0.0060 & 0.0759 & 0.2164 & -0.3715 \\
FFBQL & 0.0061 & 0.0026 & 0.0509 & 0.1286 & -0.5753 \\
OGDCL & 0.0822 & 0.0668 & 0.1221 & 0.6752 & 0.1201 \\
FFCL & 0.0065 & 0.0029 & 0.0530 & 0.1350 & -0.5269 \\
KOT ADDU PCL & 0.0070 & 0.0037 & 0.0585 & 0.1361 & -0.4847 \\
\hline
\end{tabular}

Note: Pakistan stock exchange, $\mathrm{MV}=$ mean variance, $\mathrm{SV}=$ semi variance, $\mathrm{MaD}=$ mean absolute deviation, $\mathrm{CVaR} 95 \%=$ conditional value at risk with risk confidence levels $\beta=0.95$ and $\mathrm{CVaR99} \%=$ conditional value at risk with risk confidence levels $\beta=0.99$.

Table 4. Optimal portfolio compositions for economic crisis period (2006-2009).

\begin{tabular}{cccccc}
\hline & MV & SV & MaD & CVaR95\% & CVaR99\% \\
\hline Square Limited & 0.3961 & 0.1123 & 0.2115 & 0.0159 & 0.0413 \\
RAK Ceramics Ltd. & 0.0447 & 0.0173 & 0.2180 & -0.3741 & -0.9856 \\
Grameenphone. & 0.0002 & 0.0304 & 0.1973 & 0.0037 & 0.0109 \\
Titas and Dist. Co., Ltd. & 0.4565 & 0.1795 & 0.2192 & 0.0325 & 0.0603 \\
Meghna Ltd. & 0.2701 & 0.0708 & 0.2045 & 0.0082 & 0.0284 \\
Heidelberg Cement Ltd. & 0.0211 & 0.0088 & 0.2108 & -0.2329 & -0.6032 \\
IDLC Finance Limited & 0.1514 & 0.0402 & 0.1975 & 0.0050 & 0.0148
\end{tabular}

Note: Dhaka stock exchange, $\mathrm{MV}=$ mean variance, $\mathrm{SV}=$ semi variance, $\mathrm{MaD}=$ mean absolute deviation, $\mathrm{CVaR} 95 \%=$ conditional value at risk with risk confidence levels $\beta=0.95$ and $\mathrm{CVaR} 99 \%=$ conditional value at risk with risk confidence levels $\beta=0.99$. 
Table 5. Optimal portfolio compositions for economic recovery period (2010-2013).

\begin{tabular}{cccccc}
\hline & MV & SV & MaD & CVaR95\% & 99\% \\
\hline BDCOM & 0.0144 & 0.0033 & 0.8399 & 0.1650 & -0.5225 \\
BA Tobacco & 0.0108 & 0.0034 & 0.8315 & -0.1430 & -0.3846 \\
Lafarge Cement Ltd. & 0.0151 & 0.0040 & 0.8471 & 0.1870 & -0.5138 \\
NBL & 0.0122 & 0.0046 & 0.8319 & 0.1669 & -0.4614 \\
Titas and Dist. Co., Ltd. & 0.0314 & 0.0067 & 0.8323 & -0.2143 & -0.5662 \\
IDLC Finance Limited & 0.0232 & 0.0107 & 0.8537 & -0.2473 & -0.6281 \\
ACI Limited & 0.0231 & 0.0108 & 0.8428 & -0.3010 & -0.8151 \\
Pharmaceuticals Ltd. & 0.0454 & 0.0154 & 0.8638 & 0.1926 & -0.5335 \\
Islamic Bank Bed Ltd. & 0.0118 & 0.0067 & 0.8279 & 0.1816 & -0.4809 \\
Meghna Ltd. & 0.0074 & 0.0031 & 0.8546 & -0.1456 & -0.4405 \\
Padma Co. & 0.0095 & 0.0047 & 0.8351 & 0.1835 & -0.4706 \\
BA Tobacco Bang & 0.0092 & 0.0041 & 0.8373 & -0.1803 & -0.6226 \\
BRAC Bank Ltd. & 0.0122 & 0.0043 & 0.8359 & 0.1612 & -0.4084 \\
Grameenphone. & 0.0077 & 0.0056 & 0.8567 & -0.1993 & -0.6386 \\
Heidelberg Cement Ltd. & 0.0083 & 0.0049 & 0.8540 & -0.2079 & -0.5615 \\
Square Limited & 0.0171 & 0.0104 & 0.8258 & -0.3007 & -0.8510 \\
BATL & 0.0075 & 0.0035 & 0.8545 & 0.1537 & -0.4132 \\
Delta Insurance & 0.0079 & 0.0044 & 0.8465 & -0.1800 & -0.4963 \\
\hline
\end{tabular}

Note: Dhaka stock exchange, $\mathrm{MV}=$ mean variance, $\mathrm{SV}=$ semi variance, $\mathrm{MaD}=$ mean absolute deviation, $\mathrm{CVaR} 95 \%=$ conditional value at risk with risk confidence levels $\beta=0.95$ and $\mathrm{CVaR99} \%=$ conditional value at risk with risk confidence levels $\beta=0.99$.

Table 6. Optimal portfolio compositions for economic growth period (2014-2015).

\begin{tabular}{cccccc}
\hline & MV & SV & MaD & CVaR95\% & CVaR99\% \\
\hline Aftab Automobiles & 0.0612 & 0.0053 & 0.4048 & 0.2520 & 0.0450 \\
Padma Co. & 0.0513 & 0.0026 & 0.3920 & 0.2042 & 0.0463 \\
Olympic Ltd. & 0.0532 & 0.0030 & 0.3946 & 0.2328 & 0.0460 \\
Jamuna Oil Com. Ltd. & 0.0982 & 0.4532 & 0.4565 & 0.4114 & -6.0997 \\
RAK Ceramics Ltd. & 0.0441 & 0.0023 & 0.3891 & 0.1948 & 0.0493 \\
Delta Insurance & 0.0912 & 0.0208 & 0.4089 & 0.3201 & 0.0261 \\
BSRM Steels & 0.0920 & 0.0678 & 0.4144 & 0.3409 & 0.0174 \\
Pubali Bank & 0.1793 & 0.4921 & 0.4506 & 2.1221 & 0.0498 \\
Heidelberg Cement Ltd. & 0.0734 & 0.0150 & 0.4069 & 0.3129 & 0.0314 \\
Summit Power Ltd. & 0.0244 & 0.0018 & 0.3823 & -0.1868 & -0.0727 \\
Titas and Dist. Co., Ltd. & 0.0223 & 0.0017 & 0.3798 & -0.1816 & -0.0951 \\
NBL & 0.0545 & 0.0031 & 0.3969 & 0.2365 & 0.0459 \\
Beximco Pharma & 0.0131 & 0.0012 & 0.3763 & -0.0898 & -0.1242 \\
BDCOM & 0.0081 & 0.0026 & 0.4068 & -0.2547 & -0.6520 \\
Pharmaceuticals Ltd. & 0.0272 & 0.0020 & 0.3841 & 0.1934 & 0.0385 \\
Lafarge Cement Ltd. & 0.0599 & 0.0041 & 0.4039 & 0.2399 & 0.0452 \\
Meghna Ltd. & 0.0572 & 0.0039 & 0.3971 & 0.2378 & 0.0455 \\
Square Limited & 0.0062 & 0.0150 & 0.4044 & -0.3673 & -1.4223 \\
BRAC Bank Ltd. & 0.0823 & 0.0167 & 0.4077 & 0.3145 & 0.0282 \\
Grameenphone. & 0.0962 & 0.3485 & 0.4321 & 0.3950 & -0.6841 \\
BDFINANCE & 0.0044 & 0.0027 & 0.3969 & -0.2408 & -0.7403 \\
IDLC Finance Ltd. & 0.0632 & 0.0059 & 0.4062 & 0.2737 & 0.0421 \\
UCBL & 0.0176 & 0.0015 & 0.3774 & -0.1651 & -0.1191 \\
BATL & 0.0323 & 0.0015 & 0.3797 & -0.1934 & -0.5952 \\
\hline
\end{tabular}

Note: Dhaka stock exchange, $\mathrm{MV}=$ mean variance, $\mathrm{SV}=$ semi variance, $\mathrm{MaD}=$ mean absolute deviation, $\mathrm{CVaR} 95 \%=$ conditional value at risk with risk confidence levels $\beta=0.95$ and CVaR99\% $=$ conditional value at risk with risk confidence levels $\beta=0.99$. 
Table 7. Optimal portfolio compositions for economic crisis period (2004-2007).

\begin{tabular}{cccccc}
\hline & MV & SV & MaD & CVaR95\% & CVaR99\% \\
\hline NTPC Ltd. & 0.2324 & 0.2098 & 0.2453 & 0.331 & 0.0223 \\
Bosch Ltd. & 0.0722 & 0.0217 & 0.1438 & 0.0422 & 0.0004 \\
Maruti Suzuki India Ltd. & 0.2251 & 0.1872 & 0.2355 & 0.3235 & 0.0094 \\
Eicher Motors Ltd. & 0.1006 & 0.0456 & 0.1558 & 0.1121 & 0.0005 \\
ONGC Ltd. & 0.2422 & 0.2164 & 0.2526 & 0.3323 & 0.0332 \\
Dabur India Ltd. & 0.0919 & 0.0410 & 0.1547 & 0.0534 & 0.0005 \\
Mahindra \& Mahindra Ltd. & 0.2224 & 0.1844 & 0.2329 & 0.3234 & 0.0087 \\
Canara Bank & 0.0752 & 0.0230 & 0.1476 & 0.0432 & 0.0004 \\
ABB India Ltd. & 0.1037 & 0.1752 & 0.1728 & -1.1277 & -2.9871 \\
Asian Paints Ltd. & 0.1440 & 0.3302 & 0.1438 & -1.1062 & -5.0733 \\
Godrej Consumer Ltd. & 0.1225 & 0.0681 & 0.1655 & 0.1222 & 0.0007 \\
Exide Industries Ltd. & 0.1037 & 0.0539 & 0.1571 & 0.1122 & 0.0005 \\
Sun Pharmaceutical Ltd. & 0.1340 & 0.1306 & 0.1490 & -1.0832 & -2.9161 \\
Bharat Heavy Electricals Ltd. & 0.0678 & 0.0203 & 0.1386 & 0.0344 & 0.0003 \\
Infosys Ltd. & 0.1674 & 0.1360 & 0.2108 & 0.2423 & 0.0035 \\
HDFC Ltd. & 0.1332 & 0.0811 & 0.1728 & 0.1323 & 0.0007 \\
GMR Infrastructure Ltd. & 0.1120 & 0.0611 & 0.1617 & 0.1213 & 0.0006 \\
Colgate-Palmolive Ltd. & 0.0845 & 0.0253 & 0.1490 & 0.0443 & 0.0004 \\
Hero MotoCorp Ltd. & 0.1340 & 0.0857 & 0.1767 & 0.2121 & 0.0007 \\
ITC Ltd. & 0.3007 & 0.5054 & 0.2540 & -1.9406 & -4.9598 \\
Punjab National Bank & 0.2685 & 0.2420 & 0.2540 & 0.3333 & 0.0343 \\
Lupin Ltd. & 0.2123 & 0.1752 & 0.2259 & 0.3232 & 0.0076 \\
Titan Company Ltd. & 0.4523 & 0.4644 & 0.3579 & 0.5232 & 0.0080 \\
HDFC Bank Ltd. & 0.1340 & 0.0823 & 0.1759 & 0.1324 & 0.0907 \\
ACC Ltd. & 0.1662 & 0.0062 & 0.1271 & -0.2256 & -0.7054 \\
Bharti Airtel Ltd. & 0.0707 & 0.0213 & 0.1417 & 0.0422 & 0.0004 \\
\hline Boman
\end{tabular}

Note: Bombay stock exchange, $\mathrm{MV}=$ mean variance, $\mathrm{SV}=$ semi variance, $\mathrm{MaD}=$ mean absolute deviation, $\mathrm{CVaR} 95 \%=$ conditional value at risk with risk confidence levels $\beta=0.95$ and CVaR99 $\%=$ conditional value at risk with risk confidence levels $\beta=0.99$.

Table 8. Optimal portfolio compositions for economic recovery (2008-2011).

\begin{tabular}{cccccc}
\hline & MV & SV & MaD & CVaR95\% & CVaR99\% \\
\hline NMDC Ltd. & 0.0316 & 0.0218 & 0.1147 & 0.4523 & 0.0087 \\
Infosys Ltd. & 0.0248 & 0.0162 & 0.1095 & 0.3453 & 0.0035 \\
Sun Pharmaceutical Ltd. & 0.0637 & 0.1203 & 0.1421 & 0.5345 & 0.0563 \\
Lupin Ltd. & 0.0281 & 0.0202 & 0.1133 & 0.4342 & 0.0065 \\
Bharat Electricals Ltd. & 0.0111 & 0.0051 & 0.0777 & 0.0452 & 0.0003 \\
Titan Company Ltd. & 0.1247 & 0.2642 & 0.1722 & 0.5634 & 0.0908 \\
Tata Global Beverages Ltd. & 0.2044 & 0.4486 & 0.1964 & 0.6453 & 0.1323 \\
Cipla Ltd. & 0.0138 & 0.0066 & 0.0851 & 0.1233 & 0.0004 \\
Dabur India Ltd. & 0.0155 & 0.0075 & 0.0908 & 0.2234 & 0.0005 \\
Nestle India Ltd. & 0.0331 & 0.0228 & 0.1162 & 0.4534 & 0.0097 \\
Tata Consultancy Ltd. & 0.0175 & 0.0172 & 0.0850 & -0.3327 & -1.2194 \\
Godrej Consumer Ltd. & 0.0177 & 0.0098 & 0.0968 & 0.2352 & 0.0007 \\
Bharti Airtel Ltd. & 0.0132 & 0.0058 & 0.0810 & 0.0535 & 0.0043 \\
Hindustan Unilever Ltd. & 0.0054 & 0.0023 & 0.0578 & -0.1173 & -0.2943 \\
Colgate-Palmolive Ltd. & 0.0042 & 0.0018 & 0.0459 & -0.1147 & -0.3271 \\
\hline
\end{tabular}

Note: Bombay stock exchange, $\mathrm{MV}=$ mean variance, $\mathrm{SV}=$ semi variance, $\mathrm{MaD}=$ mean absolute deviation, $\mathrm{CVaR95 \%}=$ conditional value at risk with risk confidence levels $\beta=0.95$ and $\mathrm{CVaR} 99 \%=$ conditional value at risk with risk confidence levels $\beta=0.99$. 
Table 9. Optimal portfolio compositions for economic growth period (2012-2015).

\begin{tabular}{cccccc}
\hline & MV & SV & MaD & CVaR95\% & CVaR99\% \\
\hline State Bank of India & 0.0185 & 0.2063 & 0.1685 & 0.6403 & 0.2232 \\
Infosys Ltd. & 0.0148 & 0.0334 & 0.1204 & 0.5345 & 0.0563 \\
Dabur India Ltd. & 0.0069 & 0.0049 & 0.0636 & 0.2342 & 0.0007 \\
NTPC Ltd. & 0.0196 & 0.0016 & 0.0482 & 0.0245 & 0.0002 \\
Nestle India Ltd. & 0.0202 & 0.0033 & 0.0587 & 0.1344 & 0.0005 \\
Axis Bank Ltd. & 0.1143 & 0.1853 & 0.1789 & -1.1342 & -3.3683 \\
Asian Paints Ltd. & 0.1165 & 0.3855 & 0.1884 & -1.1382 & -4.7054 \\
HCL Technologies Ltd. & 0.0041 & 0.0014 & 0.0500 & -0.0953 & -0.2664 \\
Dr. Reddy's Lab. Ltd. & 0.0039 & 0.0023 & 0.0482 & -0.1292 & -0.3482 \\
United Breweries Ltd. & 0.0942 & 0.0061 & 0.0681 & 0.3233 & 0.0009 \\
Hindustan Unilever Ltd. & 0.0105 & 0.0044 & 0.0605 & 0.2324 & 0.0006 \\
Glenmark Pharma Ltd. & 0.0071 & 0.0051 & 0.0581 & -0.1811 & -0.6612 \\
Jindal Steel Ltd. & 0.0153 & 0.0049 & 0.0633 & 0.2332 & 0.0006 \\
Idea Cellular Ltd. & 0.0025 & 0.0012 & 0.0386 & 0.0095 & 0.0067 \\
Wipro Ltd. & 0.0057 & 0.0031 & 0.0536 & -0.1655 & -0.4858 \\
Divi's Laboratories Ltd. & 0.0701 & 0.0025 & 0.0509 & 0.0453 & 0.0043 \\
Tata Consultancy Ltd. & 0.0311 & 0.0014 & 0.0432 & 0.0232 & 0.0002 \\
ITC Ltd. & 0.0134 & 0.0012 & 0.0386 & 0.0132 & 0.0005 \\
Cairn India Ltd. & 0.0056 & 0.0013 & 0.0534 & -0.1050 & -0.3090 \\
\hline
\end{tabular}

Note: Bombay stock exchange, $\mathrm{MV}=$ mean variance, $\mathrm{SV}=$ semi variance, $\mathrm{MaD}=$ mean absolute deviation, $\mathrm{CVaR} 95 \%=$ conditional value at risk with risk confidence levels $\beta=0.95$ and CVaR99\% = conditional value at risk with risk confidence levels $\beta=0.99$.

Markowitz (1952) describes that finding the right mix of stocks (risky assets) in terms of expected return and variance of return, that is, an optimal portfolio in terms of yield and risk, is the greatest challenge for an investor. A simple principle for the optimal stock composition is that the highest returning portfolio is not automatically the lowest risk (variance) portfolio. We use four risk measures in every scenario and their results are quite different from each other. These models are utilized to develop ideal portfolio from 40 accessible firms listed on the Pakistani stock exchange.

Choosing a model depends highly on the risk attitude of an investor. However, rather than being risk averse or a risk taker, he/she may choose an optimal portfolio with low risk and high returns. Table 1, presenting optimal portfolio composition for economic crises, explains that MCB make up the maximum percentage in optimal portfolios respectively for all four measures. Furthermore, it explains that $\mathrm{MCB}$ invested the most where investors invest $36.41 \%$ of funds in $\mathrm{MCB}$ if he/she chooses to employ the MV model, $36.79 \%$ funds are invested for SV model, $22.17 \%$ if MaD model is used, $40.60 \%$ of funds are used for employing CVaR (95\%) and 9.89\% of funds are invested when using CVaR (99\%) model.

According to Pakistan's annual GDP recovery rate, this scenario is built where four risk models yields distinctive optimal portfolios for economic period of recovery. It is found that when investors are willing to take more risk, either the expected return of a portfolio increases, or a risk averse investor is able to decrease the variance in trade for a lower expected return. From Table 2 it is assumed that during economic recovery, PPL makes up the highest proportion of optimal portfolio. If an investor opts for an MV model, he/she invests up to $20.49 \%$ in aforesaid security. $\mathrm{He} /$ she invests $5.14 \%$ of funds when using an SV model, $20.95 \%$ for MaD, $25.27 \%$ for CVaR (95\%) and $13.81 \%$ of investment for the CVaR (99\%) model.

It is implied that ample diversification is based on the quantity of shares, and volatility is minimized by diversification across sectors and industries. Companies in the same sector typically display high covariance between themselves in general as they respond similarly to economic events that lead to greater risk exposure. Consequently, when a prescribed level of risk earns the maximum possible expected return, an investor carries an MV-efficient portfolio (Campbell et al. 1997). A financial specialist can decrease the risk of his investment by diversifying it over various stocks. From Table 3 , it is examined that during the economic growth period, OGDCL invested the most where it is deduced 
that an investor puts $8.22 \%$ of funds in OGDCL if he/she chooses to opt for the MV model, 6.68\% if SV model is employed, $12.21 \%$ for MaD model, $67.52 \%$ if CVaR (95\%) model is chosen and $12.01 \%$ for CVaR (99\%). It can also be examined that CVaR (99\%) provides negative returns for all securities except OGDCL during this period.

If we summarize the results for the Pakistan stock exchange during the periods of crises, recovery and growth, it can be said that MCB made the highest proportion in optimal portfolio in the crisis period and in the case of recovery and growth, the highest proportion lies with PPL and OGDCL, respectively. The results are similar for all types of risk measures. It shows that these securities are able to attract more investment in any scenario.

Literature stats that portfolio theory affects the management of money and other assets worldwide. From Table 4, it is concluded that during economic crises in Dhaka Stock Exchange, Titas and Dist. Co., Ltd. remains the riskiest security in the optimal portfolio for all risk measures. It makes up the highest proportion in optimal portfolio. Investors invest $45.65 \%$ of funds in Titas and Dist. Co., Ltd. if they opt for the MV model, $17.95 \%$ investments when using the SV model, $21.92 \%$ for employing the MaD Model, 3.25\% funds are invested in the case of CVaR (95\%) and 6.03\% funds are invested if investors choose the CVaR (99\%) model.

By analyzing all the optimal portfolios from Table 5, it is stated that during the time of economic recovery, Pharmaceuticals Ltd. comprises the highest risk. By considering the fact that high risk leads to high return, investors tends to invest $4.54 \%$ of their funds into this particular security while they choose the MV risk model. This proportion is $1.54 \%$ for using the SV model, $86.36 \%$ for the MaD model and $19.26 \%$ for CVaR (95\%). It can also be examined that CVaR (99\%) provides negative returns for all securities during this period.

This research reveals that the multiperiod issue can be resolved as a series of single-period issues under many sets of rational assumptions. However, if only one period is analyzed, the optimal portfolio will be different from that which is chosen. The distinction occurs because in the multiperiod case, the relevant utility function is a derived that takes multiple periods into account. Independence of returns between periods is one principle behind multiperiod portfolio research. In the last decade, there has been considerable research showing that mean returns and variances are correlated over time and are components of variables that are easily noticeable (Fama and French 1989; Campbell and Shiller 1988).

In Table 6, optimal portfolios are created for economic period of growth for Bangladesh market. This table shows that Pubali Bank comprises the highest risk. In order to receive high returns, investors are willing to invest in risky securities. It can be deduced that investors tend to invest $17.93 \%$ of their funds into this particular security while they choose the MV risk model. This proportion is $49.21 \%$ for using the SV model, 212\% for employing the CVaR (95\%) model and $4.96 \%$ funds are invested if investors opt for the CVaR (99\%) model for optimal portfolio selection. However, if they choose the MaD model, the highest proportion is made by Jamuna Oil Com. Ltd.

From the above discussion, it can be concluded that for each of the scenario, top risky securities continue to change. Investors choose securities for investment by keeping the nature of economic condition in mind. They also choose securities depending on their investing attitude. Risk averse investors choose less risky securities and hence get low profits/returns. Whereas, risk takers invest in risky securities to get high returns. They prefer high returns, so they are more likely to choose the optimal portfolio. Diversification can keep them safe from risks so they may choose different securities in single scenario.

Table 7 presents results for the Bombay stock exchange about portfolio composition in the time of economic crises. The results reveal that investors invest $45.23 \%$ of their funds in Titan Company Ltd. if they choose the MV model, $46.44 \%$ if they choose the SV model, $35.79 \%$ investment is for the $\mathrm{MaD}$ model and this percentage is about $52.32 \%$ in the case of choosing CVaR (95\%). However, if they choose CVaR (99\%), they invest $9.07 \%$ of their funds in HDFC Bank Ltd. 
The four risk models build distinctive ideal portfolio creations for the economic period of recovery. From Table 8 it is deduced that during the time of economic recovery, Tata Global Beverages Ltd. gives up the highest risk level in the optimal portfolios for all risk indicators. This particular security is the riskiest so the returns for investing in this security under different risk measures are also high. In order to receive high returns, investors invest $20.44 \%$ of their funds in Tata Global Beverages Ltd. if they choose the MV model, $44.86 \%$ is invested for the SV model, $19.64 \%$ for using the MaD model, $64.53 \%$ of funds are allocated if the CVaR (95\%) model is selected and $13.23 \%$ for CVaR (99\%).

For Bombay stock exchange, these four risk measures again give distinctive portfolios creations for each of the scenario. From Table 9 it is deduced that during the time of economic growth, Asian Paints Ltd. remains the riskiest security in the optimal portfolios for all risk measures except when the CVaR (95\%) and CVaR (99\%) models are employed. For these two models, the riskiest security is State Bank of India. From the above results, it is concluded that with the change of economic conditions, investor's investment decisions also change. In the decline, recovery and growth phase, their motive is to invest in those securities which generate more returns. They also prefer to invest in more than one security for minimizing risks. For this purpose, they are more inclined towards choosing the optimal portfolio.

From the above tables, it is evident that the top risky securities, in different scenarios, keeps on changing. It is not necessary that a security which is risky in the period of crisis stays risky in recovery and growth period. So, it totally depends on the investor's attitude, portfolio type and nature of economy (or economic scenario) that which the security (or group of securities) is to be selected for the portfolio. The risks associated with security also impact the decision. Similarly, risk measures also have direct influence on choosing the optimal structure as each model does not perform equally well in each economic scenario. In addition, a model performing better in crises phases does not necessarily yield the same results in recovery or growth period.

The summary statistics of the optimal portfolios in three different economic sub periods of Pakistan, Bangladesh and India are shown in Appendix A. For Pakistan, the average rate of return calculated for the period is $9.31 \%$, which is the average risk-free rate from the period 2003 to 2015 . This average rate of return is not achieved for all models in each scenario. This implies all portfolios developed are not ready to produce returns at any rate identical to the risk-free return. CVaR (95\%) gives the best results for all optimal portfolios in each scenario of Pakistan. The results about mean returns are highest during the growth time period (2012-2015) for portfolios created by the CVaR (95\%), MV, MaD and SV models. However, CVaR (99\%) yields low or negative returns. From risk perspectives, as appeared by the portfolios' variance and skewness during the economic crisis investors bring more risk. Model CVaR (95\%) provides the highest portfolio skewness during recovery period. Positive skewness is desirable as it decreases the probability of getting extreme negative returns. Results are consistent with each scenario. Hence, the $\mathrm{CVaR}(95 \%)$ is the most appropriate risk measure to control downside risk. Comparison of CVaR (95\%) and CVaR (99\%) is also shown in Appendix B.

For Bangladesh, the average required rate of return calculated for the period is $5.75 \%$. Again, this average rate of return is not achieved for all models in each scenario. During the recovery period (2010-2013), mean returns are highest for all portfolios created by each of these four risk models. However, the portfolios developed by the CVaR (95\%) model provides the maximum returns. Results with respect to skewness indicates that the CVaR (95\%) model provides the highest skewness during the economic growth period. Results are consistent as model CVaR (95\%) yields outstanding results in each scenario for the Dhaka stock exchange. These findings suggest that the MV, SV and MAD models are unable to develop optimal portfolios with maximum returns in each scenario. Thus, The CVaR $(95 \%)$ model is the most suitable portfolio optimization model for all three economic scenarios.

For India, the minimum required rate of return for the period is $7.89 \%$, which is the average risk-free rate from the period 2004 to 2015. Again, this average rate of return is not achieved for all models, but crisis and growth periods yield return more than their average in specific scenario. Results of the Bombay stock exchange show that mean returns are highest during the crises time 
period (2004-2007) for all portfolios produced by these four risk models. Portfolios that are built by utilizing CVaR (95\%) demonstrate the highest returns. From risk perspectives, as appeared by the portfolios' variances and skewness during the economic crisis' economic specialists bring about more risks. Portfolios that are built by utilizing the CVaR (95\%) model also gives the highest skewness during periods of economic crisis. For the Indian market the results are also consistent because CVaR $(95 \%)$ gives outstanding results in each economic scenario but the trend is different from the country perspective. Similar to the other two countries, CVaR (99\%) does not perform likewise for this market but CVaR (95\%) yields outstanding results.

The merits and demerits of each risk measure are evident by the results. H1, H3, H5 and H6 are accepted because each of the risk measure has its impact on the portfolio performance. However, their performance is not consistent in each period, so $\mathrm{H} 4, \mathrm{H} 7$ and $\mathrm{H} 8$ are not supported. $\mathrm{H} 2$ is also supported because the performance of $\mathrm{CVaR}$ is consistent in each scenario for all three countries. This study is evident the prior studies done by Jaaman et al. (2013) that variance is not a proper risk measure for all markets and for all economic scenarios. The CVaR is fundamentally the downward risk that particularly concentrates on the descending deviations under the mean return. CVaR is a superior coordinating choice for economic specialist's recognition that is risk averse.

\section{Conclusions}

This study concludes that for Pakistan, all risk measures perform better in the growth phase, for Bangladesh they perform better in the recovery phase and for India they show better performance in the crises phase. We found that the CVaR model gave a better result in each scenario. Thereby, investors are recommended to use this model for their portfolio construction. Public and private investors are required to re-evaluate their investment portfolio to improve their investment skills. The contribution of the paper is two-fold. (i) The outcome of the current study helps to identify if the same risk assessment is applicable in all three substituent or different risk measure is required for a different sub period. (ii) It provides an insight on asset choice, management and the use of an optimal risk model to estimate expected risk and return. The implications of our findings would be beneficial for the investors, investment decision makers and policy makers not only in Pakistan, Bangladesh and India, but also those in other developing countries. Our study has some limitations. Firstly, it only covered three developing countries. It will be of great importance to conduct a study to make a comparison between developing and developed economies so that it can further validate the consistencies of these risk models. Secondly, this study focuses on four models (MV, SV, MaD, CVaR), future studies may test the applicability of other risk models such as the mean Gini (MG) model, second degree stochastic dominance (SSD) and other quadratic models. Furthermore, future research may back-test risk measures such as CVaR as conducted by Amendola and Candila (2017). Moreover, our study only considered GDP to identify different economic scenarios, and therefore some other criteria may be used to identify the economic scenario. Researchers can use other macroeconomic indicators such as interest rates, inflation, gross national product (GNP) and foreign direct investment (FDI) instead of GDP as criteria to identify different economic scenario.

Author Contributions: Conceptualization, U.S., M.H., S.C. and A.I.H.; methodology, A.I.H., M.H. and U.S.; software, U.S. and M.H.; validation, S.M.A. and S.C.; formal analysis, U.S., M.H. and A.I.H.; resources, S.M.A. and S.C.; data curation, S.M.A.; writing-original draft preparation, U.S., M.H. and A.I.H.; writing-review and editing, S.C. and S.M.A.; supervision, A.I.H. and S.M.A.; project administration, S.C. and A.I.H. All authors have read and agreed to the published version of the manuscript.

Funding: This research received no external funding.

Conflicts of Interest: The authors declare no conflict of interest. 


\section{Appendix A}

Table A1. Summary Statistics of Optimal Portfolios.

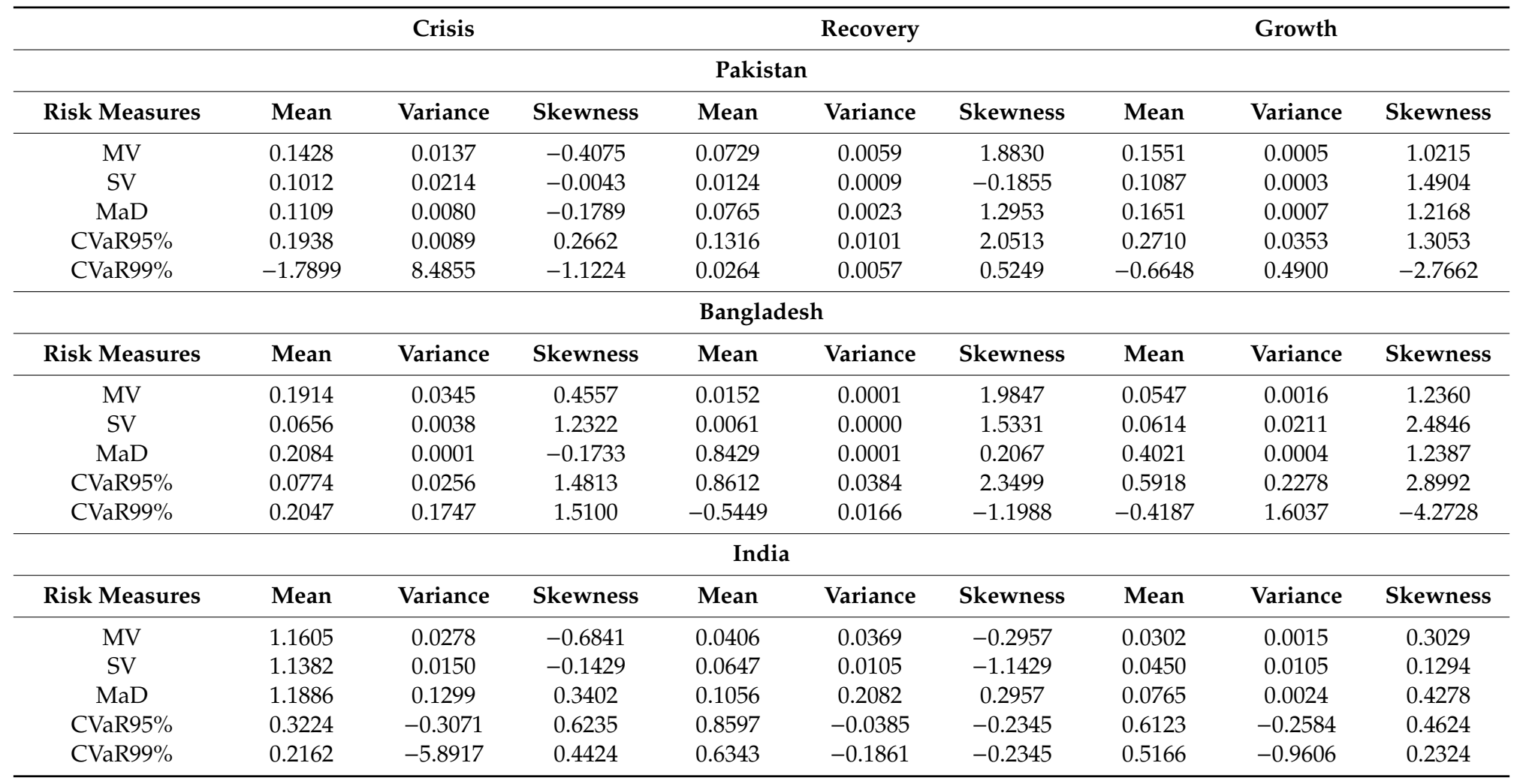

Note: $\mathrm{MV}=$ mean variance, $\mathrm{SV}=$ semi variance, $\mathrm{MaD}=$ mean absolute deviation, CVaR95\% = conditional value at risk with risk confidence levels $\beta=0.95$ and $\mathrm{CVaR} 99 \%=$ conditional value at risk with risk confidence levels $\beta=0.99$. 
Table A2. Summary Statistics of Pakistan Stock Exchange.

\begin{tabular}{|c|c|c|c|c|c|}
\hline \multicolumn{6}{|c|}{ Summary Statistics Pakistan Stock Exchange } \\
\hline S. No. & Stocks & Mean & Standard Deviation & Skewness & Count \\
\hline 1. & Oil and Gas Development Co. Limited & 0.001021 & 0.221281 & -1.50018 & 156 \\
\hline 2. & Pakistan Petroleum Limited & 0.001086 & 0.22892 & 0.276563 & 156 \\
\hline 3. & Pakistan Oilfields Limited & 0.000733 & 0.3062 & -0.26124 & 156 \\
\hline 4. & Mari Petroleum Company Limited & 0.007585 & 0.278518 & -0.50018 & 156 \\
\hline 5. & Standard Chartered Bank Limited & 0.001315 & 0.272276 & 1.111712 & 156 \\
\hline 6. & National Bank of Pakistan & 0.001448 & 0.482104 & 2.418173 & 156 \\
\hline 7. & Bank Al-Falah Limited & 0.001051 & 0.513031 & 0.976922 & 156 \\
\hline 8. & Bank of Punjab Limited & -0.002 & 0.595658 & 2.099947 & 156 \\
\hline 9. & Habib Bank Limited & 0.002073 & 0.308275 & 0.327552 & 156 \\
\hline 10. & Askari Bank Limited & 0.005141 & 0.413128 & 3.213836 & 156 \\
\hline 11. & United Bank Limited & 0.002536 & 0.333472 & 0.083406 & 156 \\
\hline 12. & Faysal Bank Limited & 0.005985 & 0.697984 & 0.817687 & 156 \\
\hline 13. & MCB Bank Limited & 0.001059 & 0.180457 & 0.212136 & 156 \\
\hline 14. & Bank Al-Habib Limited & 0.00193 & 0.433875 & -1.41979 & 156 \\
\hline 15. & Soneri Bank Limited & 0.003921 & 0.862424 & 1.055569 & 156 \\
\hline 16. & Habib Metropolitan Bank Limited & 0.004279 & 0.313162 & 2.762352 & 156 \\
\hline 17. & Meezan Bank Limited & 0.002111 & 0.387592 & 0.046732 & 156 \\
\hline 18. & Pakistan Telecommunication Co. Limited & 0.000105 & 0.332074 & -0.0121 & 156 \\
\hline 19. & TRG Pakistan Limited & 0.002827 & 0.70609 & -1.1057 & 156 \\
\hline 20. & K-Electric Limited & 0.003277 & 0.540738 & -1.62602 & 156 \\
\hline 21. & Hub Power Company Limited & 0.001326 & 0.302786 & 0.795003 & 156 \\
\hline 22. & Kot Addu Power Company Limited & 0.001105 & 0.273556 & -1.44901 & 156 \\
\hline 23. & Nishat Power Limited & 0.003869 & 0.45398 & 0.37976 & 156 \\
\hline 24. & Fauji Fertilizer Company Limited & 0.001028 & 0.283348 & -1.87297 & 156 \\
\hline 25. & Fauji Fertilizer Bin Qasim Limited & 0.001746 & 0.475096 & 0.87015 & 156 \\
\hline 26. & Engro Corporation Limited & 0.003254 & 0.523509 & -0.17939 & 156 \\
\hline 27. & Dawood Hercules Corporation Limited & 0.00338 & 0.349771 & 1.057867 & 156 \\
\hline 28. & Fauji Cement Company Limited & 0.009017 & 0.498798 & -0.42289 & 156 \\
\hline 29. & Maple Leaf Cement Factory Limited & 0.004824 & 0.576098 & -1.94281 & 156 \\
\hline 30. & D.G. Khan Cement Company Limited & 0.001742 & 0.397196 & 0.113583 & 156 \\
\hline 31. & Lucky Cement Limited & 0.005225 & 0.283228 & -0.03627 & 156 \\
\hline 32. & Pioneer Cement Limited & 0.009626 & 0.542533 & -0.57855 & 156 \\
\hline 33. & Cherat Cement Company Limited & 0.003574 & 0.60806 & -2.53044 & 156 \\
\hline 34. & Kohat Cement Limited & 0.004201 & 0.559042 & -0.82246 & 156 \\
\hline 35. & Pakistan State Oil Company Limited & 0.002733 & 0.228718 & -3.55791 & 156 \\
\hline 36. & Shell Pakistan Limited & 0.004873 & 0.352169 & 2.257017 & 156 \\
\hline 37. & Attock Petroleum Limited & 0.001572 & 0.298047 & 0.166549 & 156 \\
\hline 38. & National Foods Limited & 0.002727 & 0.390825 & -1.2129 & 156 \\
\hline 39. & Nestle Pakistan Limited & 0.002127 & 0.363435 & -0.33565 & 156 \\
\hline 40. & Murree Brewery Company Limited & 0.007543 & 0.318573 & 1.216602 & 156 \\
\hline
\end{tabular}


Table A3. Summary Statistics of Bombay Stock Exchange.

\begin{tabular}{|c|c|c|c|c|c|}
\hline \multicolumn{6}{|c|}{ Summary Statistics Bombay Stock Exchange } \\
\hline S. No. & Stocks & Mean & Standard Deviation & Skewness & Count \\
\hline 1. & ABB India Ltd. & -0.00157 & 0.233363 & -2.25599 & 156 \\
\hline 2. & ACC Ltd. & -0.00084 & 0.145414 & -1.94626 & 156 \\
\hline 3. & Aditya Birla Nuvo Ltd. & -0.00124 & 0.37893 & 0.014707 & 156 \\
\hline 4. & Ambuja Cements Ltd. & -0.00099 & 0.23382 & -1.16542 & 156 \\
\hline 5. & Ashok Leyland Ltd. & -0.0027 & 0.217722 & -1.68763 & 156 \\
\hline 6. & Asian Paints Ltd. & -0.00132 & 0.310585 & -4.627 & 156 \\
\hline 7. & Aurobindo Pharma Ltd. & -0.00211 & 0.274632 & -3.12489 & 156 \\
\hline 8. & Axis Bank Ltd. & 0.003356 & 0.296079 & -2.22231 & 156 \\
\hline 9. & Bank of Baroda & -0.00181 & 0.333875 & -1.46145 & 156 \\
\hline 10. & Bank of India & -0.00142 & 0.227189 & -0.72262 & 156 \\
\hline 11. & Bharat Forge Ltd. & -0.00235 & 0.302002 & -0.34207 & 156 \\
\hline 12. & Bharat Heavy Electricals Ltd. & -0.00127 & 0.325302 & -0.02748 & 156 \\
\hline 13. & Bharat Petroleum Corporation Ltd. & -0.00154 & 0.170063 & -1.18159 & 156 \\
\hline 14. & Bharti Airtel Ltd. & -0.00049 & 0.375371 & -0.19651 & 156 \\
\hline 15. & Bosch Ltd. & 0.012793 & 0.733424 & -0.75958 & 156 \\
\hline 16. & Cairn India Ltd. & 0.001032 & 0.145309 & 1.230483 & 156 \\
\hline 17. & Canara Bank & -0.0019 & 0.182741 & -0.41748 & 156 \\
\hline 18. & Cipla Ltd. & -0.00129 & 0.17321 & -2.20387 & 156 \\
\hline 19. & Colgate-Palmolive (India) Ltd. & -0.00092 & 0.240767 & -2.92544 & 156 \\
\hline 20. & Crompton Greaves Ltd. & -0.00123 & 0.252653 & 0.227359 & 156 \\
\hline 21. & Cummins India Ltd. & -0.00168 & 0.226236 & -3.16762 & 156 \\
\hline 22. & DLF Ltd. & $4.42 \times 10^{-5}$ & 0.235311 & 2.332312 & 156 \\
\hline 23. & Dabur India Ltd. & -0.0009 & 0.401805 & -0.82827 & 156 \\
\hline 24. & Divi's Laboratories Ltd. & -0.00069 & 0.204466 & -4.24654 & 156 \\
\hline 25. & Dr. Reddy's Laboratories Ltd. & -0.0005 & 0.38532 & -0.91409 & 156 \\
\hline 26. & Eicher Motors Ltd. & -0.00265 & 0.66675 & -1.98111 & 156 \\
\hline 27. & Exide Industries Ltd. & -0.00145 & 0.244269 & -4.96028 & 156 \\
\hline 28. & Federal Bank Ltd. & -0.00178 & 0.22905 & -0.23047 & 156 \\
\hline 29. & GAIL (India) Ltd. & -0.00061 & 0.178616 & -1.02371 & 156 \\
\hline 30. & GMR Infrastructure Ltd. & 0.000612 & 0.494066 & 1.842718 & 156 \\
\hline 31. & Glenmark Pharmaceuticals Ltd. & -0.00092 & 0.204925 & -2.17214 & 156 \\
\hline 32. & Godrej Consumer Products Ltd. & -0.0007 & 0.305101 & 0.141337 & 156 \\
\hline 33. & Grasim Industries Ltd. & -0.00084 & 0.328513 & -0.29509 & 156 \\
\hline 34. & HCL Technologies Ltd. & -0.00015 & 0.211023 & 0.315107 & 156 \\
\hline
\end{tabular}


Table A3. Cont.

\begin{tabular}{|c|c|c|c|c|c|}
\hline \multicolumn{6}{|c|}{ Summary Statistics Bombay Stock Exchange } \\
\hline S. No. & Stocks & Mean & Standard Deviation & Skewness & Count \\
\hline 35. & HDF Corporation Ltd. & -0.00098 & 0.179843 & -4.33258 & 156 \\
\hline 36. & HDFC Bank Ltd. & -0.00111 & 0.177979 & -4.51155 & 156 \\
\hline 37. & Hero MotoCorp Ltd. & -0.0013 & 0.330888 & -0.92848 & 156 \\
\hline 38. & Hindustan Petroleum Corporation Ltd. & -0.002 & 0.210976 & -0.52083 & 156 \\
\hline 39. & Hindustan Zinc Ltd. & -0.00096 & 0.266736 & -3.54545 & 156 \\
\hline 40. & Hindalco Industries Ltd. & -0.00112 & 0.17116 & 0.462405 & 156 \\
\hline 41. & Hindustan Unilever Ltd. & -0.0009 & 0.197239 & -4.04114 & 156 \\
\hline 42. & ICICI Bank Ltd. & 0.004245 & 0.473254 & -0.51326 & 156 \\
\hline 43. & IDBI Bank Ltd. & -0.00081 & 0.164191 & 0.421009 & 156 \\
\hline 44. & IDFC Ltd. & -0.00146 & 0.205183 & 0.863535 & 156 \\
\hline 45. & ITC Ltd. & 0.007871 & 0.128682 & -1.42025 & 156 \\
\hline 46. & Idea Cellular Ltd. & 0.010322 & 0.234203 & 1.782345 & 156 \\
\hline 47. & Indian Oil Corporation Ltd. & -0.00088 & 0.355123 & 1.689711 & 156 \\
\hline 48. & IndusInd Bank Ltd. & -0.0019 & 0.505213 & -2.24344 & 156 \\
\hline 49. & Infosys Ltd. & 0.002398 & 0.384179 & -0.95713 & 156 \\
\hline 50. & JSW Steel Ltd. & -0.00048 & 0.283034 & -0.32537 & 156 \\
\hline 51. & Jaiprakash Associates Ltd. & 0.001771 & 0.635872 & 1.911416 & 156 \\
\hline 52. & Jindal Steel \& Power Ltd. & 0.001708 & 0.416398 & 0.519836 & 156 \\
\hline 53. & Kotak Mahindra Bank Ltd. & -0.00172 & 0.331907 & -1.33099 & 156 \\
\hline 54. & Larsen \& Toubro Ltd. & -0.00104 & 0.396199 & 0.722518 & 156 \\
\hline 55. & LIC Housing Finance Ltd. & -0.00201 & 0.298472 & -1.41351 & 156 \\
\hline 56. & Lupin Ltd. & -0.00121 & 0.294502 & -1.55839 & 156 \\
\hline 57. & M \& M Financial Services Ltd. & -0.00087 & 0.233975 & -3.35674 & 156 \\
\hline 58. & Mahindra \& Mahindra Ltd. & -0.00084 & 0.162597 & -0.35194 & 156 \\
\hline 59. & Maruti Suzuki India Ltd. & -0.00191 & 0.217107 & -2.38063 & 156 \\
\hline 60. & NMDC Ltd. & -0.0002 & 0.433197 & 0.760369 & 156 \\
\hline 61. & NTPC Ltd. & -0.00057 & 0.348464 & -0.4629 & 156 \\
\hline 62. & Nestle India Ltd. & -0.00076 & 0.281296 & -2.53393 & 156 \\
\hline 63. & Oil and Natural Gas Corporation Ltd. & -0.00057 & 0.316139 & 2.333243 & 156 \\
\hline 64. & Power Finance Corporation Ltd. & -0.00184 & 0.233618 & -1.39979 & 156 \\
\hline 65. & Punjab National Bank & 0.003609 & 0.221933 & -1.80743 & 156 \\
\hline 66. & Reliance Capital Ltd. & -0.00128 & 0.266942 & 1.017342 & 156 \\
\hline 67. & Reliance Industries Ltd. & -0.00028 & 0.176676 & 2.922033 & 156 \\
\hline 68. & Reliance Infrastructure Ltd. & -0.00097 & 0.209109 & 1.035737 & 156 \\
\hline 69. & Reliance Communications Ltd. & 0.001353 & 0.376787 & 1.878953 & 156 \\
\hline
\end{tabular}


Table A3. Cont.

\begin{tabular}{|c|c|c|c|c|c|}
\hline \multicolumn{6}{|c|}{ Summary Statistics Bombay Stock Exchange } \\
\hline S. No. & Stocks & Mean & Standard Deviation & Skewness & Count \\
\hline 70. & State Bank of India & 0.006937 & 0.547412 & -1.00748 & 156 \\
\hline 71. & Shriram Transport Finance Co., Ltd. & -0.00164 & 0.420911 & -1.88917 & 156 \\
\hline 71. & Siemens Ltd. & -0.00125 & 0.50214 & 1.433028 & 156 \\
\hline 73. & Steel Authority of India (SAIL) Ltd. & -0.00095 & 0.449804 & -0.40762 & 156 \\
\hline 74. & Sun Pharmaceutical Industries Ltd. & -0.00087 & 0.253425 & -2.09883 & 156 \\
\hline 75. & Tata Chemicals Ltd. & -0.00139 & 0.309131 & -0.33424 & 156 \\
\hline 76. & Tata Consultancy Services Ltd. & -0.00039 & 0.212023 & 0.66793 & 156 \\
\hline 77. & Tata Global Beverages Ltd. & -0.00022 & 0.356531 & -0.47745 & 156 \\
\hline 78. & Tata Motors Ltd. & -0.00077 & 0.200697 & -3.33218 & 156 \\
\hline 79. & Tata Power Company Ltd. & -0.00023 & 0.399376 & -1.04622 & 156 \\
\hline 80. & Tata Steel Ltd. & -0.00041 & 0.206793 & -1.74184 & 156 \\
\hline 81. & Tech Mahindra Ltd. & -0.00102 & 0.268141 & -1.61563 & 156 \\
\hline 82. & Titan Company Ltd. & -0.0014 & 0.30896 & -6.30429 & 156 \\
\hline 83. & UPL Ltd. & -0.00169 & 0.247734 & -1.23392 & 156 \\
\hline 84. & UltraTech Cement Ltd. & -0.00118 & 0.484679 & -1.1287 & 156 \\
\hline 85. & Union Bank of India & -0.0021 & 0.568566 & -2.31036 & 156 \\
\hline 86. & Unitech Ltd. & -0.00095 & 0.832437 & 0.732133 & 156 \\
\hline 87. & United Breweries Ltd. & $-6.8 \times 10^{-5}$ & 0.315536 & -1.69065 & 156 \\
\hline 88. & United Spirits Ltd. & -0.00042 & 0.265947 & -1.52575 & 156 \\
\hline 89. & Vedanta Ltd. & -0.00048 & 0.427308 & -4.16601 & 156 \\
\hline 90. & Wipro Ltd. & 0.000183 & 0.279398 & -1.0839 & 156 \\
\hline 91. & YES Bank Ltd. & -0.0023 & 0.350807 & -1.20037 & 156 \\
\hline 92. & Zee Entertainment Enterprises Ltd. & 0.003819 & 0.124231 & -0.9429 & 156 \\
\hline
\end{tabular}


Table A4. Summary Statistics of Dhaka Stock Exchange.

\begin{tabular}{|c|c|c|c|c|c|}
\hline \multicolumn{6}{|c|}{ Summary Statistics Dhaka Stock Exchange } \\
\hline S. No. & Stocks & Mean & Standard Deviation & Skewness & Count \\
\hline 1. & ACI Limited & 0.004334 & 0.350274 & 1.663434 & 156 \\
\hline 3. & Aftab Autos & 0.004728 & 0.371382 & -2.16318 & 156 \\
\hline 4. & BA Tobacco & 0.003842 & 0.33855 & -0.48418 & 156 \\
\hline 5. & BA Tobacco Bang & 0.006408 & 0.56416 & -0.00198 & 156 \\
\hline 6. & BATL & 0.010952 & 0.367048 & 1.758986 & 156 \\
\hline 9. & Beximco Pharma & 0.008049 & 0.356722 & -1.40479 & 156 \\
\hline 10. & BRAC Bank Ltd. & 0.001536 & 0.491285 & -2.03121 & 156 \\
\hline 11. & BSRM Limited & 0.010723 & 0.460103 & -1.64063 & 156 \\
\hline 12. & BSRM Steels & 0.007602 & 0.324726 & 0.372816 & 156 \\
\hline 13. & Delta Insurance & 0.006416 & 0.384159 & 0.57767 & 156 \\
\hline 14. & Grameenphone. & 0.003052 & 0.264329 & -1.21256 & 156 \\
\hline 19. & Lafarge Cement Ltd. & 0.000457 & 0.284184 & -1.34556 & 156 \\
\hline 20. & Meghna Ltd. & $-6 \times 10^{-5}$ & 0.337869 & 0.677172 & 156 \\
\hline 21. & NBL & 0.006128 & 0.744517 & -0.65584 & 156 \\
\hline 22. & Olympic Ltd. & 0.005392 & 0.276331 & 1.910264 & 156 \\
\hline 23. & Padma Co. & 0.004012 & 0.409943 & 0.098543 & 156 \\
\hline 24. & Pharmaceuticals Ltd. & 0.00664 & 0.413572 & -0.16638 & 156 \\
\hline 25. & Pubali Bank & 0.005005 & 0.367949 & -0.37062 & 156 \\
\hline 26. & RAK Ceramics Ltd. & 0.001145 & 0.518974 & 0.768791 & 156 \\
\hline 27. & Square Limited & -0.00049 & 0.339855 & 1.707854 & 156 \\
\hline 28. & Summit Power Ltd. & 0.007812 & 0.405936 & 0.743032 & 156 \\
\hline 29. & Titas \& Dist. Co., Ltd. & 0.004302 & 0.27178 & -0.86032 & 156 \\
\hline 30. & UCBL & 0.000642 & 0.590343 & -1.70207 & 156 \\
\hline
\end{tabular}




\section{Appendix B}

Table A5. Comparison of CVaR (95\%) and CVaR (99\%).

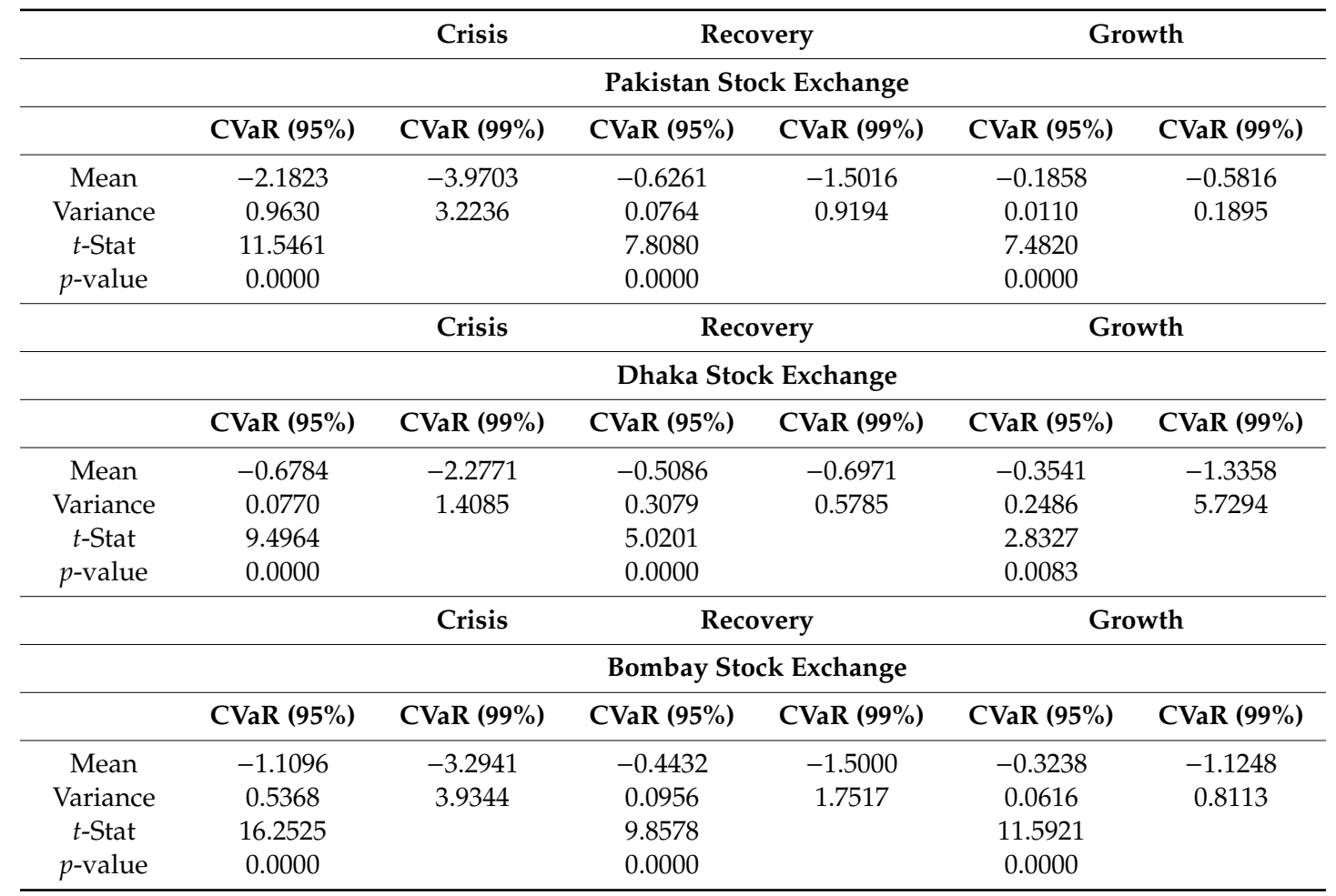

Appendix B presents the comparison of $\mathrm{CVaR}(95 \%)$ and $\mathrm{CVaR}(99 \%)$ by providing values of mean, variance, $t$-stat and $p$-values. CVaR $(95 \%)$ has higher mean and smaller variances as compared to $\mathrm{CVaR}(99 \%)$ for all three stock exchanges under each scenario. The values of $t$-stat are significant for the Pakistan stock exchange, Dhaka stock exchange and Bombay stock exchange under each scenario. However, values of t-stat are slightly higher in crisis period for all three stock exchanges as compared to recovery and growth period. Results indicates that CVaR (95\%) is a better measure of risk as compared to $\mathrm{CVaR}(99 \%)$.

\section{References}

Amendola, Alessandra, and Vincenzo Candila. 2017. Comparing multivariate volatility forecasts by direct and indirect approaches. Journal of Risk 19: 6. [CrossRef]

Artzner, Philippe, Freddy Delbaen, Jean-Marc Eber, and David Heath. 1999. Coherent measures of risk. Mathematical Finance 9: 203-28. [CrossRef]

Baghdadabad, Mohammad Reza Tavakoli. 2015. An empirical analysis of funds' alternative measures in the mean absolute deviation (MaD) framework. International Journal of Emerging Markets 10: 726-46. [CrossRef]

Banihashemi, Shokoofeh, and Sarah Navidi. 2017. Portfolio performance evaluation in Mean-CVaR framework: A comparison with non-parametric methods value at risk in Mean-VaR analysis. Operations Research Perspectives 4: 21-28. [CrossRef]

Bodie, Zvi, Alex Kane, and Alan J. Marcus. 2011. Investment and Portfolio Management. Hong Kong: McGraw-Hill Irwin.

Byrne, Peter, and Stephen Lee. 2004. Different risk measures: Different portfolio compositions? Journal of Property Investment \& Finance 22: 501-11.

Campbell, John Y., and Robert J. Shiller. 1988. Stock prices, earnings, and expected dividends. The Journal of Finance 43: 661-76. [CrossRef] 
Campbell, John Y., John J. Champbell, John W. Campbell, Andrew W. Lo, Andrew W. Lo, and A. Craig MacKinlay. 1997. The Econometrics of Financial Markets. Princeton: Princeton University Press.

Chow, K. Victor, and Karen C. Denning. 1994. On variance and lower partial moment betas the equivalence of systematic risk measures. Journal of Business Finance \& Accounting 21: 231-41.

Elton, Edwin J., Martin J. Gruber, and Christopher R. Blake. 1997. Common Factors in Mutual Fund Returns. NYU Working Paper No. FIN-97-004. New York, NY, USA: American Finance Association.

Elton, Edwin J., Martin J. Gruber, and T. Clifton Green. 2007. The impact of mutual fund family membership on investor risk. Journal of Financial and Quantitative Analysis 42: 257-77. [CrossRef]

Engle, Robert, and Bryan Kelly. 2012. Dynamic Equicorrelation. Journal of Business and Economic Statistics 30: 212-28. [CrossRef]

Fama, Eugene F., and Kenneth R. French. 1989. Business conditions and expected returns on stocks and bonds. Journal of Financial Economics 25: 23-49. [CrossRef]

Filippi, Carlo, Gianfranco Guastaroba, and Maria Grazia Speranza. 2020. Conditional value-at-risk beyond finance: A survey. International Transactions in Operational Research 27: 1277-319. [CrossRef]

García, Fernando, Francisco Guijarro, and Javier Oliver. 2018. Index tracking optimization with cardinality constraint: A performance comparison of genetic algorithms and tabu search heuristics. Neural Computing and Applications 30: 2625-41. [CrossRef]

Gluzicka, Agata. 2010. Models for choosing optimal investment portfolios with two risk measures. Methods and Applications of Operational Research 10: 76-99.

Gökgöz, Fazıl, and Mete Emin Atmaca. 2017. Portfolio optimization under lower partial moments in emerging electricity markets: Evidence from Turkey. Renewable and Sustainable Energy Reviews 67: 437-49. [CrossRef]

Grootveld, Henk, and Winfried Hallerbach. 1999. Variance vs downside risk: Is there really that much difference? European Journal of Operational Research 114: 304-19. [CrossRef]

Henriques, Carla Oliveira, and Maria Elisabete Duarte Neves. 2019. A multi-objective interval portfolio framework for supporting investor's preferences under different risk assumptions. Journal of the Operational Research Society 70: 1639-61. [CrossRef]

Hunjra, Ahmed Imran, Tahar Tayachi, Rashid Mehmood, Sidra Malik, and Zoya Malik. 2020. Impact of credit risk on momentum and contrarian strategies: Evidence from South Asian markets. Risks 8: 37. [CrossRef]

Jaaman, Saiful Hafizah, Weng Hoe Lam, and Zaidi Isa. 2013. Risk measures and portfolio construction in different economic scenarios. Sains Malaysiana 42: 875-80.

Keat, Heng S. 2009. The global financial crisis: Impact on Asia and policy challenges ahead. In Federal Reserve Bank of San Francisco Proceedings. San Francisco: Federal Reserve Bank, pp. 267-76.

Konno, Hiroshi, and Hiroaki Yamazaki. 1991. Mean-absolute deviation portfolio optimization model and its applications to Tokyo stock market. Management Science 37: 519-31. [CrossRef]

Konno, Hiroshi, Hayato Waki, and Atsushi Yuuki. 2002. Portfolio Optimization under Lower Partial Risk Measures. Asia-Pacific Financial Markets 9: 127-40. [CrossRef]

Lim, Andrew E.B., J. George Shanthikumar, and Gah-Yi Vahn. 2011. Conditional value-at-risk in portfolio optimization: Coherent but fragile. Operations Research Letter 39: 163-71. [CrossRef]

Liu, Mingming, and Yan Gao. 2006. An algorithm for portfolio selection in a frictional market. Applied Mathematics and Computation 182: 1629-38. [CrossRef]

Long, Wen, Nan Li, Huiwen Wang, and Siwei Cheng. 2012. Impact of US financial crisis on different countries: Based on the method of functional analysis of variance. Procedia Computer Science 9: 1292-98. [CrossRef]

Markowitz, Harry. 1952. Portfolio selection. The Journal of Finance 7: 77-91.

Markowitz, Harry. 1959. Portfolio Selection: Efficient Diversification of Investment. Cowles Foundation Monograph No. 16. New York: Wiley.

Markowitz, Harry M., and G. Peter Todd. 1987. Mean-Variance Analysis in Portfolio Choice and Capital Markets. Hoboken: John Wiley \& Sons.

Markowitz, Harry, Peter Todd, Ganlin Xu, and Yuji Yamane. 1993. Computation of mean-semi variance efficient sets by the critical line algorithm. Annals of Operations Research 45: 307-17. [CrossRef]

Moazeni, Somayeh, Warren B. Powell, and Amir H. Hajimiragha. 2014. Mean-conditional value-at-risk optimal energy storage operation in the presence of transaction costs. IEEE Transactions on Power Systems 30: 1222-32. [CrossRef] 
Ogryczak, Włodzimierz, and Tomasz Sliwinski. 2010. Efficient portfolio optimization with conditional value at risk. Paper presented at International Multi Conference on Computer Science and Information Technology, Wisla, Poland, October 18-20; pp. 901-8.

Oyenubi, Adeola. 2020. Optimal Portfolios on Mean-Diversification Efficient Frontiers. In Advanced Studies of Financial Technologies and Cryptocurrency Markets. Singapore: Springer, pp. 35-63.

Prakash, Arun J., Chun-Hao Chang, and Therese E. Pactwa. 2003. Selecting a portfolio with skewness: Recent evidence from US, European, and Latin American equity markets. Journal of Banking E Finance 27: 1375-90.

Rastogi, Shailesh. 2014. The financial crisis of 2008 and stock market volatility-analysis and impact on emerging economies pre and post crisis. Afro-Asian Journal of Finance and Accounting 4: 443-59. [CrossRef]

Rockafellar, R. Tyrrell, and Stanislav Uryasev. 2000. Optimization of conditional value-at-risk. Journal of Risk 2: 21-42. [CrossRef]

Shahbaz, Muhammad, Mohamed Arouri, and Frédéric Teulon. 2014. Short-and long-run relationships between natural gas consumption and economic growth: Evidence from Pakistan. Economic Modelling 41: 219-26. [CrossRef]

Soleimani, Hamed, and Kannan Govindan. 2014. Reverse logistics network design and planning utilizing conditional value at risk. European Journal of Operational Research 237: 487-97. [CrossRef]

South Asian Financial Market Review. 2010. A Publication of the South Asian Federation of Exchanges. Kathmandu: The South Asian Association for Regional Cooperation (SAARC).

Tang, Chor Foon, and Soo Y. Chua. 2012. The savings-growth nexus for the Malaysian economy: A view through rolling sub-samples. Applied Economics 44: 4173-85. [CrossRef]

Vidovic, Jelena. 2011. Performance of risk measures in Portfolio construction on Central and South-East European emerging markets. American Journal of Operations Research 1: 236. [CrossRef]

Publisher's Note: MDPI stays neutral with regard to jurisdictional claims in published maps and institutional affiliations. 